Original Article

\title{
Acute Traumatic Subdural Hematoma: Series of Thirty Cases
}

\author{
Muhammad Asif, Waqar Aziz Rehman, Sumaira Sarwar, Hamza Younas, Aatika Younas \\ Sahiwal Medical College/DHQ Hospital, Sahiwal - Pakistan
}

\begin{abstract}
Objectives: Acute Traumatic Subdural Hematoma (ASDH) is one of the most dangerous and challenging neurosurgical problems faced by neurosurgeons. Road traffic accidents (RTAs) and falls are the most common causes of ASDH. This study focused to evaluate the incidence, mode, and severity of the injury, treatment options, and determine outcomes in patients with ASDH.
\end{abstract}

Material \& Methods: Thirty patients with ASDH were studied over a period of three years. Detailed history, general and neurological examination including GCS were noted, CT scans were done and patients managed according to said protocol.

Results: Twenty-three (76.66\%) were male and Seven (23.33\%) were female. The common mode of injury were road traffic accidents (66.66\%) and falls (26.66\%). Out of 30 patients, $53.33 \%$ had GCS $3-5$. Overall, the mortality rate was $60 \% .23 .33 \%$ of patients survived with severe disability and $10 \%$ of patients showed moderate disability and good recovery. The mortality rate was higher in patients above 50 years of age.

Conclusion: Acute traumatic subdural hematoma is still very fatal and has a high mortality. Early CT scanning emergency, surgery and good postoperative ICU care can play a role in improving the outcome in patients with ASDH.

Keywords: Acute Traumatic Subdural Hematoma (ASDH), Road Traffic Accident (RTA), Glasgow Coma Scale (GCS).

Corresponding Author: Dr. Muhammad Asif

Sahiwal Medical College/DHQ Hospital, Sahiwal - Pakistan

Email: drasif2003@gmail.com

Date of Submission: 22-04-2021

Date of Revision: 31-05-2021

Date of Online Publishing: 13-06-2021

Date of Print: 30-06-2021

DOI: $10.36552 /$ pjns.v25i2.556

\section{INTRODUCTION}

Acute traumatic subdural hematoma is a threatening issue among head injuries. It is the most challenging surgical pathology for neurosurgeons, in which a blood clot forms between the brain surface and the dura mater. Among the patients with $\mathrm{ASDH}$, a subgroup of patients' needs to be defined who can get the benefit of its surgical evacuation. It is diagnosed through a CT Scan as intracranial hyperdense and the concavo-convex assemblage of blood 
between dura and brain parenchyma, which usually involves almost the whole of the cerebral hemisphere. ${ }^{1}$ The incidence of ASDH has been reported between $12-29 \%$ in patients with severe head injury. ${ }^{2-5}$ The patients with combined mild, moderate and severe head injuries observed to have an incidence rate of $11 \%$ in $\mathrm{ASDH} .{ }^{6,7}$

The majority of patients reported with ASDH were male with an average ages between 10 and 40 years. $^{8-11}$ Road traffic accidents (RTAs), falls and assault are among the major causes of ASDH. In the younger age group, RTAs are the major cause. In one case-series study, up to $56 \%$ falls were responsible for almost $12 \%$ of $\mathrm{ASDH}$. Among elderly patients, falls were the major cause of ASDH compared to RTAs (22\%). ${ }^{12}$ Among the patients presenting in coma state RTAs were responsible for up to $75 \%$ of the ASDH, which indicated that RTAs lead to more serious injury due to high-speed accidents and associated diffuse axonal injury (DAl). 3,5,13 The vast majority of patients (up to $80 \%)^{7,8,11,14}$ with ASDH had a severe head injury with GCS $\leq 8$ and only a small percentage of the patients had GCS $\geq 9$. It is due to the fact that the majority of the patients with ASDH and GCS $\leq 8$ had associated intracranial pathology. Brain contusions, intracerebral hematoma, subarachnoid hemorrhage, and extradural hematoma are frequently associated with intracranial pathologies. ${ }^{7,14}$

ASDH is one of the lethal pathologies in head injury patients and it is still a big challenge for neurosurgeons. The mortality from ASDH varies $35-90 \%$ in different reported studies. ${ }^{17-20}$ Mortality from ASDH is affected by different factors, i.e., primary resuscitation, early referral to specialized neurosurgical units, earliest possible CT scan, diagnosis, effective surgical procedure, and postoperative ICU care. $^{18}$ The timing of surgery has been a debate as it is a critical factor, which determines the surgical outcome. But a number of recent studies have shown no big difference in mortality rates among patients with
ASDH whether the surgery was performed within four hours of injury or after four hours of injury. ${ }^{21}$ Recently, it has been suggested that the age and type of surgical procedure are the major factors affecting the outcome of patients with ASDH especially those with GCS $4-6$ i.e., in severe head injury. ${ }^{16}$ The current study aimed to evaluate the incidence, mode, and severity of the injury, treatment options and to determine the outcome in patients with ASDH.

\section{MATERIAL AND METHODS}

\section{Study Design \& Setting}

This study was conducted on thirty patients with ASDH (Acute Traumatic Subdural Hematoma) who were enrolled in Department of Neurosurgery DHQ Teaching Hospital/Sahiwal Medical College, Sahiwal for three years i.e., from January 2017 to December 2019. Most of our patients were referred from surrounding $\mathrm{DHQ}$ (District Headquarters) and THQ (Tehsil Headquarters) Hospitals, where Neurosurgical facilities were not available and the majority of them had severe head injuries.

\section{Inclusion Criteria}

All the patients were resuscitated following standard protocols i.e., ATLS. The vitally stable general physical examination was ensured and neurological examination was done including GCS (Glasgow coma scale). The patients were then shifted for CT Scan brain. Those patients who had acute traumatic subdural haematoma were included in this study.

\section{Exclusion Criteria}

Patients with polytrauma having serious extracranial injuries were not included in this study. 


\section{Clinical and Surgical Management}

The mode of injury, timing of the injury, level of unconsciousness (GCS), operative procedure, and final outcome were noted. Patients with ASDH with more than $10 \mathrm{~mm}$ thick and more than $5 \mathrm{~mm}$ midline shift were operated in an emergency. Associated brain injuries were analyzed and recorded. Mannitol 1 gram per $\mathrm{kg}$ was given and patients shifted to the operation theatre for craniotomy/craniectomy and evacuation of ASDH. Duraplasty was done in only a few cases where there was brain swelling and brain contusion. Neurological outcome was determined by recording the Glasgow outcome scale.

\section{RESULTS}

\section{Age Distribution}

Twenty-five (83.33\%) were below 50 years of age and only 5 (16.66\%) were above 50 years.

\section{Gender Distribution}

$76.66 \%$ were male patients and $23.33 \%$ were female patients, with male to female ratio almost 3:1.

\section{Modes of Injuries}

The most common mode of injury was the road traffic accident (RTA). 20 patients (66.66\%) reported injuries from RTA falls reported in 8 patients (26.66\%) and two patients (6.66\%) had a history of assault (Table 1). Figure 1 shows the acute subdural hematoma with underlying brain contusions and midline shift.

\section{Neurological Assessment}

Table 2 shows the association of GCS with the outcome in all patients. The neurological assessment was based on GCS. Out of thirty patients, 16 (53.33\%) had GCS $3-5$. Out of these sixteen patients, 12 (75\%) died and 4 (25\%) survived with poor functional outcomes i.e., severe disability and vegetative state.

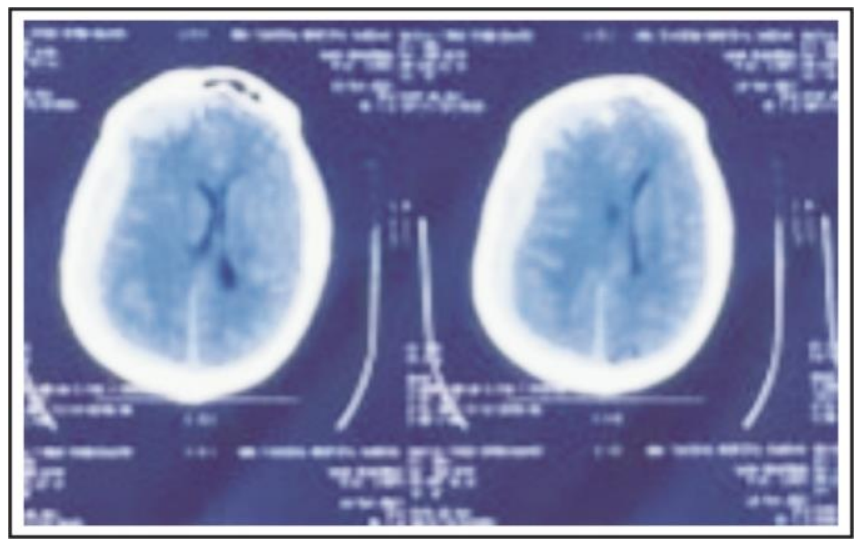

Figure 1: Acute subdural hematoma with underling brain contusions and midline shift.

Table 1: Distribution of 30 Patients for Age, Sex \& Modes of Injury.

\begin{tabular}{lcc|} 
Age Group & $\begin{array}{c}\text { Number of } \\
\text { Patients }\end{array}$ & Percentage \\
$<50$ years & 25 & $83.33 \%$ \\
$>\quad 50$ years & 5 & $16.66 \%$ \\
Sex & & \\
Male & 23 & $76.66 \%$ \\
Female & 7 & $23.33 \%$ \\
Mode of Injury & & \\
Falls & 8 & $66.66 \%$ \\
Road traffic accident & 20 & $26.66 \%$ \\
Sport injury\& fire area injury & 2 & $6.66 \%$ \\
\hline
\end{tabular}

Ten (33.33\%) patients had GCS 6 - 8, among them, 5 (50\%) patients died, 2 (20\%) survived with severe disability, whereas, $3(30 \%)$ had a good functional recovery.

Only four patients had GCS $9-12$, one of them (25\%) died, one (25\%) survived with severe disability and two (50\%) showed a good recovery.

Overall, out of total thirty patients, 18 died showing a mortality rate of $60 \%$. Seven out of thirty $(23.33 \%)$ patients survived with severe disability and three (10\%) patients showed moderate disability and good recovery. A good 
functional outcome means a GOS grade of good recovery and/or moderate disability.

\section{Age and GCS}

Out of five patients with age more than 50 years (elderly patients), four with GCS below 8 died with a mortality rate of $80 \%$. Among 25 patients, with ages below 50 years, 23 had GCS below 8, and fourteen died with $56 \%$ mortality rate. This showed that the mortality rate was higher in patients above 50 years of age.

\section{DISCUSSION}

The incidence of ASDH has been reported in 12$29 \%$ in patients with severe head injury. ${ }^{2-5}$ In spite of rapid and early $\mathrm{CT}$ scanning, diagnosis, and neurosurgical interventions, the mortality rate reported in $50-90 \% \cdot{ }^{17-23}$ Hatashita et $\mathrm{al}^{16}$ has reported a mortality rate of $55 \%$ and functional recovery as $30 \%$ in patients with ASDH. The acute subdural hematoma was evacuated by craniotomy and/or decompressive craniectomy depending on GCS, the estimated volume of subdural collection and midline shift, and associated intracranial pathologies. The aim of surgical intervention was to give enough space to the brain to relax and restore its functions. ${ }^{25}$ Most studies have demonstrated that the majority of the patients with ASDH were adult males. A study by Ryan et $\mathrm{al}^{26}$ showed shown that $63 \%$ of patients with ASDH were male. Yanagawa et a ${ }^{27}$ has reported $67 \%$ of male patients with ASDH with a mean age of 43 years. In a study by Alago et $\mathrm{al}_{1}{ }^{24} 79.8 \%$ of patients were male with a mean age of 47 years. In our study, $76.66 \%$ of the patients were male with a mean age of 45 years and these figures are inconsistent with the abovementioned studies. It has been well believed that road traffic accidents, falls, occupational accidents, and higher rates of assaults are more common in adult males. Males are more exposed to the outside environment, especially in countries like Pakistan, here people are more involved in risky works and driving as compared to females. Yanagawa el $\mathrm{al}^{27}$ has stated that ASDH has resulted as most common from RTAs. In another study, RTAs were followed by falls and were the two most common causes of ASDH. ${ }^{28}$ Kaptanaglu et a ${ }^{29}$ had mentioned similar statistics for ASDH. In our study, $66.66 \%$ of patients had injuries from road traffic accidents and $26.66 \%$ of patients suffered from falls being the cause of ASDH. The mortality rate in patients with ASDH varies from $40-60 \% .^{30-31}$

Many factors including age, GCS at the time of presentation, the timing of surgery, and associated intracranial pathologies play important role in ultimate outcome. Gennarelli et a ${ }^{32}$ has reported patients with GCS 3-4 had 74\% mortality and GCS $6-8$ had $36 \%$ mortality. Leitgeb et al ${ }^{30}$ reported a mortality rate as $47 \%$ and with associated intracranial pathologies, the mortality rate was increased as the GCS lowered. Shen et $\mathrm{al}^{33}$ have reported that the lower the GCS, the higher the mortality. In our study, the overall mortality was $60 \%$. In patients with GCS $3-5$, the mortality was $75 \%$ and with GCS $6-8$ it was $50 \%$. The ultimate outcome of patients with ASDH was better in younger age patients as compared to elderly patients. ${ }^{34-36}$ Howard et a $1^{18}$ had reported the mortality rates as $74 \%$ and $18 \%$ in patients above 65 years and 18 - 40 years of age. Hatashita et al ${ }^{16}$ reported that the patients above 65 years had a mortality of $74 \%$ as compared to 
$33 \%$ in patients age $10-40$ years. In our study, the patients above 50 years had a mortality of $80 \%$ as compared to patients below 50 years (56\%). The reason for increased mortality in elderly patients might be the increased rate of associated medical illnesses, decreased physiological reserve as a whole, and decreased elasticity of the aging brain.

\section{CONCLUSION}

In spite of all the developments in the field of medicine and especially in neurosurgery, the ASDH is still very fatal and has high mortality rates. Increasing age, pre-operative GCS, and associated intracranial pathology on CT scans are supposed to be important factors predicting the mortality of such patients. Timely resuscitation and referral to specialized Neurosurgical units, early CT scans, emergency surgical intervention, and postoperative ICU care play role in improving such patients with ASDH.

\section{REFERENCES}

1. Bullock MR, Chesnut R, Ghajar J, Gordon D, Hartl R, Newell DW, Servadei F, Walters BC, Wilberger J. Surgical management of traumatic brain injury. Neurosurgery, 2006; 58 (3): 16-24.

2. Ersahin $Y$, Mutluer S. Posterior fossa extradural hematomas in children. Pediatric Neurosurgery, 1993; 19 (1): 31-3.

3. Seelig JM, Becker DP, Miller JD, Greenberg RP, Ward JD, Choi SC. Traumatic acute subdural hematoma: major mortality reduction in comatose patients treated within four hours. New England Journal of Medicine, 1981; 304 (25): 1511-8.

4. Servadei F, Nasi MT, Cremonini AM, Giuliani G, Cenni $P$, Nanni A. Importance of a reliable admission Glasgow Coma Scale score for determining the need for evacuation of posttraumatic subdural hematomas: a prospective study of 65 patients. Journal of Trauma and Acute Care Surgery, 1998; 44 (5): 868-73.

5. Wilberger JE, Harris M, Diamond DL. Acute subdural hematoma: morbidity, mortality, and operative timing. Journal of Neurosurgery, 1991; 74 (2): 212-8.

6. Massaro F, Lanotte M, Faccani G, Triolo C. One hundred and twenty-seven cases of acute subdural haematoma operated on. Actaneurochirurgica. 1996; 138 (2): 185-91.

7. Servadei, MT Nasi, G. Giuliani, A. Maria Cremonini, P. Cenni, D. Zappi, GS Taylor F. CT prognostic factors in acute subdural haematomas: the value of the 'worst' CT scan. British Journal of Neurosurgery, 2000; 14 (2): 110-6.

8. Dent $D L$, Croce MA, Menke PG, Young BH, Hinson MS, Kudsk KA, Minard G, Pritchard FE, Robertson JT, Fabian TC. Prognostic factors after acute subdural hematoma. Journal of Trauma and Acute Care Surgery, 1995; 39 (1): 36-43.

9. Gabl M, Mohsenipour I, Benedetto K. Acute posttraumatic subdural hematoma in advanced age. Unfallchirurgie. 1989; 15 (6): 273-8.

10. Koc RK, Akdemir H, Öktem IS, Meral M, Menkü A. Acute subdural hematoma: outcome and outcome prediction. Neurosurgical Review, 1997; 20 (4): 239-44.

11. Massaro F, Lanotte M, Faccani G, Triolo C. One hundred and twenty-seven cases of acute subdural haematoma operated on. Actaneurochirurgica. 1996; 138 (2): 185-91.

12. Howard MA, Gross AS, Dacey RG, Winn HR. Acute subdural hematomas: an age-dependent clinical entity. Journal of Neurosurgery, 1989; 71 (6): 85863.

13. Kotwica Z, Brzeziński J. Acute subdural haematoma in adults: an analysis of outcome in comatose patients. Actaneurochirurgica. 1993; 121 (3): 95-9.

14. Cordobés F, Lobato RD, Rivas JJ, Muñoz MJ, Chillón D, Portillo JM, Lamas E. Observations on 82 patients with extradural hematoma: comparison of results before and after the advent of computerized tomography. Journal of Neurosurgery, 1981;54 (2): 179-86.

15. Van den Brink WA, Zwienenberg M, Zandee SM, Van der Meer L, Maas Al, Avezaat CJ. The prognostic importance of the volume of traumatic epidural and subdural haematomas revisited. Actaneurochirurgica. 1999; 141 (5): 509-14.

16. Hatashita S, Koga N, Hosaka Y, Takagi S. Acute subdural hematoma: severity of injury, surgical intervention, and mortality. Neurologia Medico- 
Chirurgica. 1993; 33 (1): 13-8.

17. Haselsberger K, Pucher R, Auer LM. Prognosis after acute subdural or epidural haemorrhage. Actaneurochirurgica. 1988; 90 (3): 111-6.

18. Howard MA, Gross AS, Dacey RG, Winn HR. Acute subdural hematomas: an age-dependent clinical entity. Journal of Neurosurgery, 1989; 71 (6): 85863.

19. Jamieson KG, Yelland JD. Surgically treated traumatic subdural hematomas. Journal of Neurosurgery, 1972; 37 (2): 137-49.

20. Richards $T$, Hoff J. Factors affecting survival from acute subdural hematoma. Surgery, 1974; 75 (2): 253-8.

21. Wilberger $J E$, Harris $M$, Diamond DL. Acute subdural hematoma: morbidity, mortality, and operative timing. Journal of Neurosurgery, 1991; 74 (2): 212-8.

22. Seelig JM, Becker DP, Miller JD, Greenberg RP, Ward JD, Choi SC. Traumatic acute subdural hematoma: major mortality reduction in comatose patients treated within four hours. New England Journal of Medicine, 1981; 304 (25): 1511-8.

23. Stone JL, Lowe RJ, Jonasson OL, Baker RJ, Barrett JO, Oldershaw JB, Crowell RM, Stein RJ. Acute subdural hematoma: direct admission to a trauma center yields improved results. The Journal of Trauma, 1986; 26 (5): 445-50.

24. Alagoz $F$, Yildirim $A E$, Sahinoglu $M$, Korkmaz $M$, Secer M, Celik H, Yel C, Guvenc Y, Uckun OM, Narin F, Daglioglu E. Traumatic acute subdural hematomas: analysis of outcomes and predictive factors at a single center. Turk Neurosurg. 2017; 27 (2): 187-91.

25. Li LM, Kolias AG, Guilfoyle MR, Timofeev I, Corteen EA, Pickard JD, Menon DK, Kirkpatrick PJ, Hutchinson PJ. Outcome following evacuation of acute subdural haematomas: a comparison of craniotomy with decompressive craniectomy. Actaneurochirurgica. 2012; 154 (9): 1555-61.

26. Ryan CG, Thompson RE, Temkin NR, Crane PK, Ellenbogen RG, Elmore JG. Acute traumatic subdural hematoma: current mortality and functional outcomes in adult patients at a Level I trauma center. The Journal of Trauma and Acute Care Surgery, 2012; 73 (5): 1348.
27. Subdural NR, Delik HO. Results of single burr hole drainage for acute subdural hematoma with nonreactive pupil. Turkish Neurosurgery, 2012; 22 (2): 196-9.

28. Wilberger $J E_{1}$ Harris $M$, Diamond $D L$. Acute subdural hematoma: morbidity, mortality, and operative timing. Journal of Neurosurgery, 1991; 74 (2): 212-8.

29. Kaptanoğlu E, Solaroğlu I, Uçar MD, Okutan MO, Beşkonakli E, Taşkin Y. Acute subdural hematomas: surgical treatment. Retrospective analysis of 73 cases. Ulusaltravmadergisi $=$ Turkish Journal of Trauma \& Emergency Surgery: TJTES. 2001; 7 (4): 246-9.

30. Leitgeb J, Mauritz W, Brazinova A, Janciak I, Majdan M, Wilbacher I, Rusnak M. Outcome after severe brain trauma due to acute subdural hematoma. Journal of Neurosurgery, 2012; 117 (2): 324-33.

31. Meyer S, Gibb T, Jurkovich GJ. Evaluation and significance of the pupillary light reflex in trauma patients. Annals of Emergency Medicine, 1993; 22 (6): 1052-7.

32. Gennarelli TA, Spielman GM, Langfitt TW, Gildenberg PL, Harrington T, Jane JA, Marshall LF, Miller JD, Pitts LH. Influence of the type of intracranial lesion on outcome from severe head injury: a multicenter study using a new classification system. Journal of Neurosurgery, 1982; 56 (1): 26-32.

33. Shen J, Pan JW, Fan ZX, Zhou YQ, Chen Z, Zhan RY. Surgery for contralateral acute epidural hematoma following acute subdural hematoma evacuation: five new cases and a short literature review. Actaneurochirurgica. 2013; 155 (2): 335-41.

34. Berger MS, Pitts LH, Lovely $M$, Edwards MS, Bartkowski HM. Outcome from severe head injury in children and adolescents. Journal of Neurosurgery, 1985; 62 (2): 194-9.

35. Braakman R, Habbema JD, Gelpke GJ. Prognosis and prediction of outcome in comatose head injured patients. Modern Concepts in Neurotraumatology, 1986: 112-7.

36. Jennett BO, Teasdale G, Braakman R, Minderhoud J, Knill-Jones R. Predicting outcome in individual patients after severe head injury. The Lancet. 1976; 307 (7968): 1031-4. 


\section{Additional Information}

Disclosures: Authors report no conflict of interest.

Ethical Review Board Approval: The study was conformed to the ethical review board requirements.

Human Subjects: Consent was obtained by all patients/participants in this study.

Conflicts of Interest:

In compliance with the ICMJE uniform disclosure form, all authors declare the following:

Financial Relationships: All authors have declared that they have no financial relationships at present or within the previous three years with any organizations that might have an interest in the submitted work.

Other Relationships: All authors have declared that there are no other relationships or activities that could appear to have influenced the submitted work.

\section{AUTHORS CONTRIBUTIONS}

\begin{tabular}{|l|l|l|}
\hline Sr.\# & Author's Full Name & Intellectual Contribution to Paper in Terms of: \\
\hline 1. & Muhammad Asif & Study design and methodology. \\
\hline 2. & Muhammad Asif & Paper writing, referencing, data calculations and \\
\hline 3. & Waqar Aziz Rehman & Data collection and calculations. \\
\hline 4. & Sumaira Serwar & Analysis of data and interpretation of results etc. \\
\hline 5. & Muhammad Asif & Literature review and manuscript writing. \\
\hline 6. & Sumaira Serwar & Analysis of data and quality insurer. \\
\hline
\end{tabular}

